\title{
Natural Ventilation Control to Enhance the Performance of Building Envelope with Integrated Phase Change Material for Passive Applications in Summer
}

\author{
Cristina Piselli ${ }^{1,2}$, Alvaro de Gracia ${ }^{1,3}$, Mohit Prabhakar ${ }^{3}$, Anna Laura Pisello ${ }^{1,2}$, Luisa F. Cabeza ${ }^{3}$ \\ ${ }^{1}$ CIRIAF - Interuniversity Research centre, University of Perugia, Perugia, Italy \\ ${ }^{2}$ Department of Engineering, University of Perugia, Perugia, Italy \\ ${ }^{3}$ GREiA Research Group, INSPIRES Research Centre, University of Lleida, Lleida, Spain
}

\begin{abstract}
The potential of phase change materials (PCMs) as passive strategy for building energy efficiency is wellacknowledged. This work explores the enhancement of PCMs passive cooling performance by an effective control of natural ventilation in residential buildings. Numerical analysis via coupled dynamic simulation and optimization analysis is carried out for different climate zones in Italy. Results show that the sole PCM integrations in the internal building envelope provides negligible performance improvement. However, the control of natural ventilation based on free-cooling availability is able to enhance the efficiency of PCMs thermal energy storage charge-discharge cycle. Accordingly, significant building cooling need reduction is achievable through the optimum coupling of PCMs and natural ventilation control, especially in the coldest climates.
\end{abstract}

\section{Introduction}

Given the relevant role played by the building sector in global energy need, the implementation of sustainable and effective technologies for the design of more energy efficient and comfortable buildings is required. Among parameters affecting indoor environmental quality and thermal comfort in buildings, natural ventilation is a significant variable related to occupant behaviour to be carefully taken into account since the preliminary design stage (Pisello et al., 2016). In this study, the impact of the variation of natural ventilation control on the effective integration of Phase Change Material (PCM) in the building envelope as passive strategy for building energy efficiency (Saffari et al., 2017) is assessed. In fact, PCM integration in envelope components was demonstrated to be effective for the enhancement of building thermal-energy performance, when efficiently designed (Baetens et al., 2010). In particular, free cooling is achievable when selecting a PCM that is suitable for the specific climate conditions (Antony Aroul Raj and Velraj, 2010).

In this view, natural ventilation can affect the process of PCM thermal energy storage charge and discharge paths (de Gracia et al., 2016). These strategies have been combined for system application to design a PCM/air system able to store latent heat and increase heat transfer when coupled to the ventilation system (Borderon et al. 2015). On the other hand, Liu et al. (2018) numerically evaluated the cooling energy storage potential during night-time of a ventilated Trombe wall integrated with PCMs. As regards phase change materials integration in the building envelope, Figueiredo et al. (2017) studied the optimization of melting temperature and enthalpy for PCM panels incorporated into gypsum board partition walls and into suspended ceilings, when varying natural ventilation flow rates. The optimum configuration allowed more than $30 \%$ overheating reduction in the room with PCM panels. Similarly, Memarian et al. (2018) showed that PCM implementation allows to reduce HVAC system working hours in transition seasons by $20 \%$ when coupled with natural ventilation. Focusing on cold climates, an experimental study of phase change materials embedded in a highly glazed south oriented façade demonstrated efficient thermal storage during the whole year (Guarino et al., 2017). However, the system has to be coupled with natural ventilation for an effective PCM charge-discharge cycle during mid-seasons and summer.

In this panorama and based on the findings of a previous study on the impact of natural ventilation on building energy requirement at inter-building scale (Pisello et al., 2016), now a more advanced approach is used to evaluate the effect of natural ventilation on PCM performance for building envelope applications. Validated dynamic simulation coupled with optimization analysis is used to assess the performance of building walls with PCM inclusions, when varying the indoor convection heat transfer mechanism. In detail, different natural ventilation rates are entered into the building model to show the associated variation in the PCM charge and discharge cycles. Then, the novel contribution of this study is to define the most effective control strategy for natural ventilation, which allows the optimization of building envelope passive cooling performance for standard residential buildings (de Gracia et al., 2015). Similar analyses have been already carried out for the office building typology. Nevertheless, the analysis of residential buildings provides an added value to this field of research since occupants have a higher control of natural ventilation at home, which is usually more random and unpredictable than in offices (Fabi et al. 2013). Therefore, a wider analysis involving several indoor conditions, in terms of both natural and air-conditioning related ventilation, is required in this building typology, which is preliminary 
addressed in the study focusing on natural ventilation role.

Finally, although this study is focused on the Italian climate zones as case study conditions, results can be generalized for similar climate contexts and easily replicated in a variety of climate conditions around the world.

\section{Methods}

The methodology is based on numerical analysis coupling building thermal-energy dynamic simulation and optimization analysis. In detail, the role of natural ventilation control is investigated with the purpose of maximizing the passive cooling potential of PCMs when integrated into building envelopes. Furthermore, the analysis is carried out for different boundary climate conditions.

To this aim, the ASHRAE standard building model for mid-rise apartment building (ASHRAE, 2016) is selected as validated case study building. Therefore, different building scenarios are considered as follows:

1. Base scenario (Base): standard building without PCM integration in the envelope and without natural ventilation.

2. Optimized PCMs scenario (OptPCM): standard building with PCM integrated in the internal components of the building envelope, after the identification of the optimum PCM melting temperature in each climate zone. In detail, $1.5 \mathrm{~cm}$ thick PCM layer is integrated in the internal partitions and ceilings of the building. In this study, organic phase change materials are selected and the characteristics of the different typologies are defined according to existing commercial product RT25 PCM from Rubitherm (2019), which physical properties are reported in Table 1. Therefore, to define the optimum PCM peak melting temperature in each climate zone among various, hypothetical PCM peak melting temperatures were considered from $20{ }^{\circ} \mathrm{C}$ to $30{ }^{\circ} \mathrm{C}$ with reference temperature at $-20{ }^{\circ} \mathrm{C}$ and melting range of $4{ }^{\circ} \mathrm{C}$ by following the procedure described in Saffari et al. (2018). The density change of the PCM due to liquid and solid transition is considered negligible, while the enthalpy is dependent on temperature variation. The range of considered PCM types is selected in compliance with standard indoor comfort conditions in residential buildings in summer (European Committee for Standardization, 2007).

3. Optimized PCMs scenario with night-time ventilation (OptPCM_NV): standard building with PCM integration and natural ventilation during night hours (from 12:00 a.m. to 6:00 a.m.) by considering three ventilation rates, i.e. (i) $5 \mathrm{ac} / \mathrm{h}$ (air changes per hour), (ii) $10 \mathrm{ac} / \mathrm{h}$, and (iii) $15 \mathrm{ac} / \mathrm{h}$, for a wide analysis of the effect of airflow on the performance of PCM integrated in the building envelope.
4. Optimized PCMs scenario with free-cooling-based ventilation control (OptPCM_FC): standard building with PCM integration and natural ventilation control based on free-cooling availability (i.e. activated when outdoor temperature is minimum $3^{\circ} \mathrm{C}$ lower than indoors) by considering the same three ventilation rates, i.e. (i) $5 \mathrm{ac} / \mathrm{h}$, (ii) 10 $\mathrm{ac} / \mathrm{h}$, and (iii) $15 \mathrm{ac} / \mathrm{h}$.

Table 1: Physical properties of Rubitherm RT25 PCM (Rubitherm, 2019).

\begin{tabular}{|c|c|}
\hline Physical property & Value \\
\hline Melting area & $22-26{ }^{\circ} \mathrm{C}$ \\
\hline Specific heat & $2 \mathrm{~kJ} / \mathrm{kg} \mathrm{K}$ \\
\hline Thermal conductivity (both phases) & $0.2 \mathrm{~W} / \mathrm{m} \mathrm{K}$ \\
\hline $\begin{array}{c}\text { Heat storage capacity } \\
\text { (combination of latent and sensible heat } \\
\text { in a temperature range of } 16^{\circ} \mathrm{C} \text { to } 31^{\circ} \mathrm{C} \text { ) }\end{array}$ & $210 \mathrm{~kJ} / \mathrm{kg}$ \\
\hline
\end{tabular}

Accordingly, the following steps of analysis are carried out:

- Simulation of the building energy need for cooling in summer for the Base scenario in each climate zone;

- Dynamic simulation-coupled optimization analysis aimed at defining the optimum melting point of PCMs integrated in the internal building envelope in order to minimize building cooling energy need in each considered climate context;

- Simulation of the building energy need for cooling in summer for the Optimized PCMs scenario in each climate zone;

- Simulation of the building energy need for cooling in summer for the Optimized PCMs scenario with night-time ventilation in each climate zone;

- Simulation of the building energy need for cooling in summer for the Optimized PCMs scenario with freecooling-based ventilation control in each climate zone;

- Comparison of results and selection of the optimum natural ventilation control in each climate zone.

Finally, eight building scenarios are assessed in five climate zones and compared in terms of total energy need for cooling in summer. Therefore, a total of forty scenarios are evaluated.

\section{Numerical modelling}

Numerical analysis is performed through the acknowledged simulation engine EnergyPlus v8.4 (Crawley et al., 2000). Such whole-building thermalenergy simulation program allows, among other, the modelling of natural ventilation control, by defining the air changes in the different hours of the day, and also allows the modification of materials thermal properties, e.g. phase change materials (Crawley et al., 2001).

For the correct simulation of PCMs, the Conduction Finite Difference (CondFD) algorithm is selected among the available calculation algorithms with 60 time steps per hour (U.S. DOE, 2016; Saffari et al., 2018).

In order to assess building energy performance in summer, cooling energy need is calculated for the four 
warmest months in the considered climate zones, i.e. from June to September.

\section{Optimization analysis}

The coupled optimization analysis is developed via the generic optimization program GenOpt v3.1.1 (Wetter, 2000). In fact, this tool can be coupled with several simulation engines, e.g. EnergyPlus, to solve building energy performance optimization problems developed via dynamic simulation. In detail, it performs optimization of a user-defined objective function to be minimized, in this case cooling energy need, which depends on selected independent variables. Therefore, optimization problems solved through GenOpt are generally defined by the following equation (1):

$$
\min _{x \in X} f(x)
$$

Where $f: X \rightarrow \mathbf{R}$ is the objective function specified by the user, which measures the system performance, and $X$ is the constraint set of design alternatives defined by the user for the independent variable $x$. More detailed information on the optimization problem definition are described in (Piselli et al., 2017).

In this work, the optimization analysis is used to identify the optimum melting temperature of PCMs (independent variable) to be integrated in the internal building components in order to minimize building energy need for cooling (objective function) in summer. Therefore, the objective function of this one-dimensional optimization analysis can be defined as in the following equation (2):

$$
f(x)=Q_{\text {cooling }}\left(T_{m, P C M}\right)
$$

Among the various integrated mathematical optimization algorithms implemented in GenOpt, the hybrid Generalized Pattern Search algorithm (GPS) with Particle Swarm Optimization algorithm (PSO) is used in this study for an accurate evaluation and not to get trapped in local optima (Evins, 2013).

\section{Case study}

In order to consider different climate boundary conditions, the study is performed for one representative city in each of the Italian climate zones. The Italian regulatory framework (Presidente della Repubblica Italiana, 1993) classifies Italy into six climate zones, according to the heating degree days (HDD). No legislative standard defines the summer cooling zoning. Zones range from the coldest zone $\mathrm{F}$ up to the hottest zone A, characterized by HDD lower than 700, which correspond to zone Dfc (Subarctic climate) and zone Csa (Hot-summer Mediterranean climate), respectively, according to Köppen-Geiger classification (Kottek et al., 2006). However, zone A includes only the small Lampedusa island and no weather data series is available for this area. Therefore, only five case study cities are considered in the study, i.e. (i) Palermo (zone B), (ii) Naples (zone C), (iii) Rome (zone D), (iv) Milan (zone E), and (v)Tarvisio (zone F).

Regarding the case study building, the ASHRAE standard prototype building model for mid-rise apartment building (ASHRAE, 2016) is considered as validated model. The building presents a four-floor rectangular prism shape with eight apartments per floor and a central distribution area (Figure 1). Each apartment is modelled as a separated thermal zone part of the same building and, thus, considering the internal thermal mass of each thermal zone. In the model, for internal mass, wooden furniture with 6-inch width is considered. The main technical characteristics of standard building envelope components are shown in Figure 1. With respect to the validated building model, only the thermal resistance of the main envelope components, i.e. external wall, roof, ground floor, and window, is increased to achieve acceptable U-value in all the climates according to the minimum requirements of the Italian regulation (Repubblica Italiana, 2015). U-values are set based on the HDD of each selected city. Accordingly, some models present $\mathrm{U}$-values lower than those required by the regulation, because, when stricter, the characteristics of the standard ASHRAE model are kept. Table 2 reports the HDD and CDD (cooling degree days) for each city and the thermal transmittance in steady state (U-value) of the main building envelope components.

As for the HVAC system, given its influence on the final building energy performance (Piselli et al., 2017), Ideal Loads configuration is modelled in order to obtain building total energy need for cooling. Cooling set-point temperature is set equal to $25^{\circ} \mathrm{C}$, according to $\mathrm{EN}$ 15251:2007 (European Committee for Standardization, 2007).

Table 2: Climate zone, HDD, CDD, and main building

\begin{tabular}{|c|c|c|c|c|c|}
\hline $\begin{array}{c}\text { Köppen } \\
\text { class }\end{array}$ & $\begin{array}{c}\text { City \& } \\
\text { Zone }\end{array}$ & HDD & CDD & \multicolumn{2}{|c|}{$\begin{array}{c}\text { U-value } \\
{\left[\mathrm{W} / \mathbf{m}^{2} \mathbf{K}\right]}\end{array}$} \\
\hline \multirow[t]{4}{*}{ Csa } & \multirow{4}{*}{$\begin{array}{l}\text { Palermo } \\
\text { (B) }\end{array}$} & \multirow[t]{4}{*}{751} & \multirow[t]{4}{*}{150} & Roof & 0.19 \\
\hline & & & & Ext. wall & 0.38 \\
\hline & & & & $\begin{array}{l}\text { Ground } \\
\text { floor }\end{array}$ & 0.46 \\
\hline & & & & Window & 2.40 \\
\hline \multirow[t]{4}{*}{ Csa } & \multirow{4}{*}{$\begin{array}{l}\text { Naples } \\
\text { (C) }\end{array}$} & \multirow[t]{4}{*}{1034} & \multirow[t]{4}{*}{188} & Roof & 0.19 \\
\hline & & & & Ext. wall & 0.38 \\
\hline & & & & $\begin{array}{l}\text { Ground } \\
\text { floor }\end{array}$ & 0.40 \\
\hline & & & & Window & 2.40 \\
\hline \multirow[t]{4}{*}{ Csa } & \multirow{4}{*}{$\begin{array}{l}\text { Rome } \\
\text { (D) }\end{array}$} & \multirow[t]{4}{*}{1415} & \multirow[t]{4}{*}{168} & Roof & 0.19 \\
\hline & & & & Ext. wall & 0.33 \\
\hline & & & & $\begin{array}{l}\text { Ground } \\
\text { floor }\end{array}$ & 0.32 \\
\hline & & & & Window & 1.80 \\
\hline \multirow[t]{4}{*}{$\mathrm{Cfa}$} & \multirow{4}{*}{$\begin{array}{l}\text { Milan } \\
\text { (E) }\end{array}$} & \multirow[t]{4}{*}{2404} & \multirow[t]{4}{*}{158} & Roof & 0.19 \\
\hline & & & & Ext. wall & 0.30 \\
\hline & & & & $\begin{array}{l}\text { Ground } \\
\text { floor }\end{array}$ & 0.30 \\
\hline & & & & Window & 1.80 \\
\hline \multirow[t]{4}{*}{ Dfc } & \multirow{4}{*}{$\begin{array}{c}\text { Tarvisio } \\
\text { (F) }\end{array}$} & \multirow[t]{4}{*}{3959} & \multirow[t]{4}{*}{20} & Roof & 0.19 \\
\hline & & & & Ext. wall & 0.28 \\
\hline & & & & $\begin{array}{l}\text { Ground } \\
\text { floor }\end{array}$ & 0.28 \\
\hline & & & & Window & 1.50 \\
\hline
\end{tabular}
envelope components $U$-value for each case study city. 


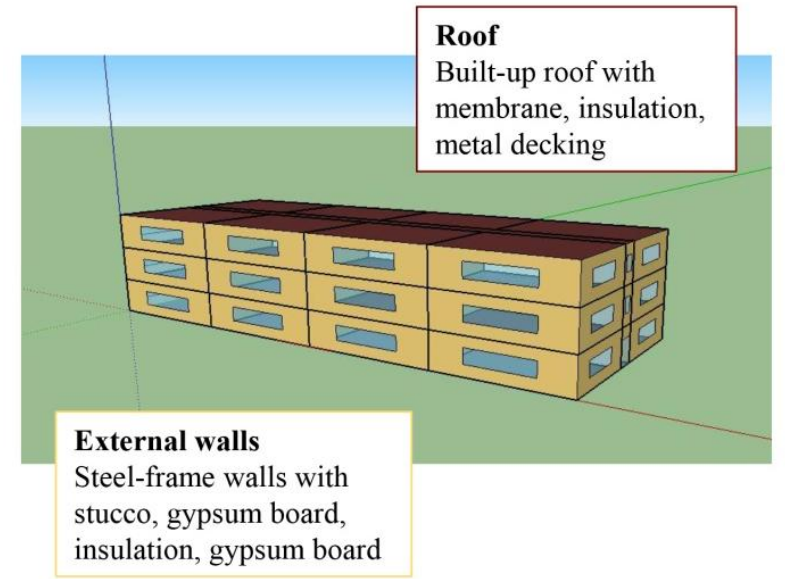

Figure 1: Case study mid-rise apartment building model and opaque envelope characteristics.

Finally, the model inputs in terms of site location and design days for each climate scenario are defined according to the EnergyPlus weather files (U.S. DOE's BTO, 2016).

\section{Results}

Firstly, results of the optimization analysis of melting point of PCM layer to be integrated in the internal building envelope is presented. Therefore, the different scenarios with and without natural ventilation control are discussed and compared.

\section{PCMs optimization}

Initially, the PCM layer thickness and location within the building envelope is investigated. Integration in both the external envelope and the internal envelope components is explored, with layer thickness from 0.5 to $1.5 \mathrm{~cm}$. Thereafter, the most suitable configuration, i.e. the sole leading to little performance improvement, is found to be $1.5 \mathrm{~cm}$ thick PCM layer located within the sole internal partitions and ceilings.

Therefore, the PCM melting temperature is optimized in each climate condition in order to minimize building energy need for cooling in summer. Figure 2 depicts the results of the optimization analysis when compared to the Base scenario, i.e. without any PCM layer. In spite of everything, the sole inclusion of PCM layer in the internal components does not show substantial building performance improvement in summer. In fact, cooling need reduction up to $716 \mathrm{kWh}$ and $715 \mathrm{kWh}$ is obtained in the hottest Naples (zone C) and Palermo (zone B), respectively. The energy saving is reduced to $580 \mathrm{kWh}$ and $359 \mathrm{kWh}$ in Tarvisio (zone F) and Rome (zone D), respectively, and even to $51 \mathrm{kWh}$ in Milan (zone E).

Nevertheless, the PCM melting temperature providing the lowest building cooling need is defined in each climate. In detail, the optimum melting point in zones B (Palermo), C (Naples), D (Rome), and F (Tarvisio) is found to be $26^{\circ} \mathrm{C}$, while it is $29^{\circ} \mathrm{C}$ in zone $\mathrm{E}$ (Milan). The significant difference in the result for zone E, i.e. humid subtropical climate, is simply due to the flatter trend in this climate context (Figure 2).

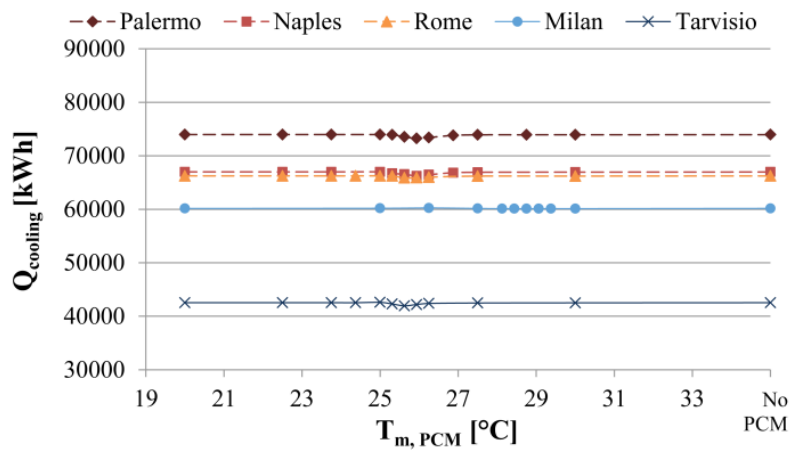

Figure 2: Building total cooling need variation with varying the PCM layer melting point in the five Italian climate zones.

\section{Natural ventilation control}

Secondly, the optimized building scenarios with the inclusion of PCM layer in the internal building envelope are simulated in each climate zone by varying the natural ventilation rate. As previously mentioned, three scenarios for night-time (12:00 a.m. - 6:00 a.m.) natural ventilation rate and the same three for free-coolingrelated natural ventilation control are explored. Figures 3 and 4 show the variation of total building cooling need in summer with varying natural ventilation rate during night-time and controlled depending upon the temperature difference between outdoor and indoor for free-cooling, respectively. The scenario with ventilation rate equal to $0 \mathrm{ac} / \mathrm{h}$ corresponds to the $O p t P C M$ scenario in each climate.

Night-time natural ventilation appears to worsen building energy performance in summer in the coolingdominated climates, i.e. Naples, Rome, and mainly in the hottest Palermo. Moreover, cooling need increases when increasing the number of air changes per hour. This means the even during night the high outdoor temperature do not allow the correct discharge of thermal energy stored by PCMs. Therefore, the best natural ventilation control is by allowing only $5 \mathrm{ac} / \mathrm{h}$ exchange. On the contrary, in the coldest climates, i.e. Milan and Tarvisio, night ventilation slightly improves building energy performance and mainly with the highest explored rate, i.e. $15 \mathrm{ac} / \mathrm{h}$, which is best performing among the $O p t P C M \_N V$ scenarios.

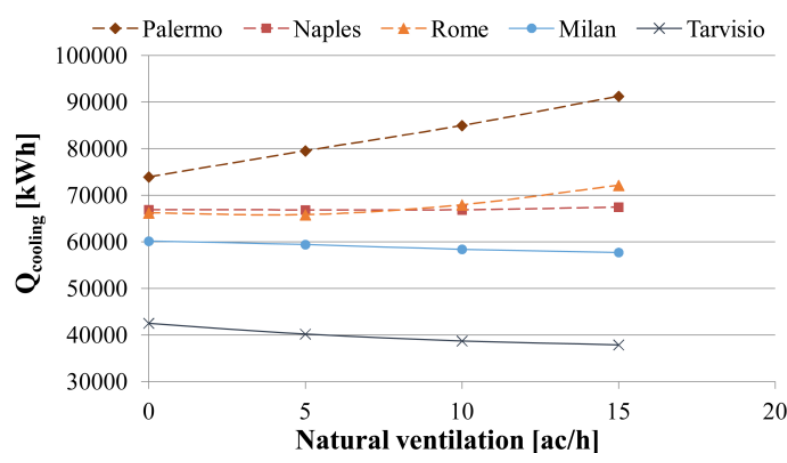

Figure 3: Building total cooling need variation with optimum PCM layer melting point and with varying night-time natural ventilation rate in the five Italian climate zones. 


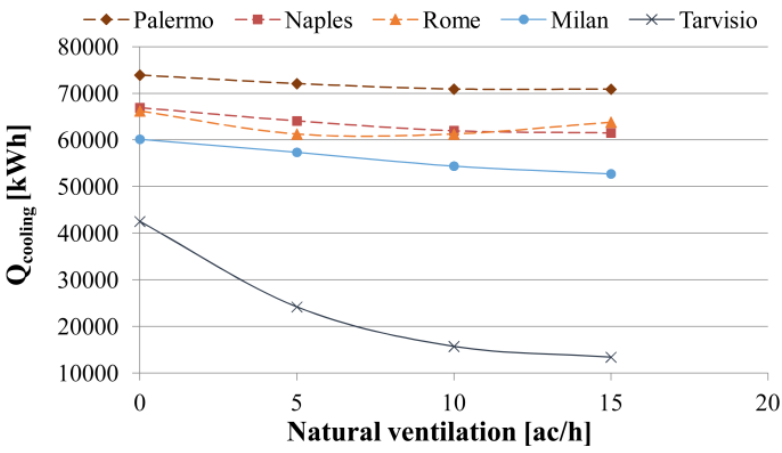

Figure 4: Building total cooling need variation with optimum PCM layer melting point and with varying freecooling-based ventilation rate in the five Italian climate zones.

On the other hand, free-cooling-based natural ventilation control is able to enhance PCM passive cooling efficiency in all analyzed climates. The performance is especially improved in the coldest climates, i.e. Milan (zone E) and Tarvisio (zone F). In this last climate context, the energy need for cooling is dampened down up to make the installation of cooling system almost negligible (summer energy need equal to $4.9 \mathrm{kWh} / \mathrm{m}^{2}$ ). Therefore, the optimum control of natural ventilation based on free-cooling availability involves an exchange rate equal to $15 \mathrm{ac} / \mathrm{h}$ in all considered climate zones, except in the mild climate of Rome (zone D).

\section{Discussion}

Figure 5 reports the variation of cooling energy need in each considered climate zone in the different scenarios. In particular, the Base scenario, the OptPCM scenario, and the best performing scenario among the $O p t P C M \_N V$ and the $O p t P C M \_F C$ series (selected based on the previous results), respectively, are compared. The comparison of the main scenarios highlights how the proposed solution appears to be slightly effective for building energy performance improvement in summer in the hottest climate zones, corresponding to Csa zone according to Köppen-Geiger classification. In fact, cooling need is negligibly improved or even increased when coupling PCMs and night natural ventilation (Table 3 ). When switching to free-cooling-based ventilation control, the performance improvement is still up to $8.1 \%, 7.5 \%$, and $4.2 \%$ in Naples, Rome, and Palermo, respectively.

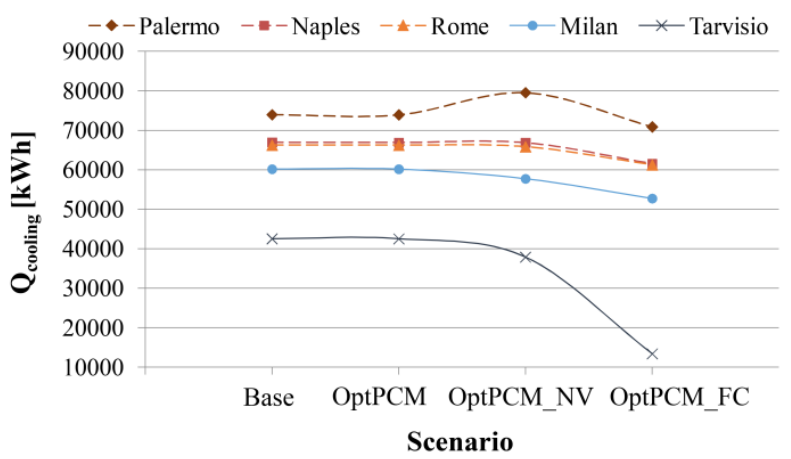

Figure 5: Building total cooling need variation for the assessed scenarios in the five Italian climate zones.
On the other hand, significant energy efficiency can be potentially achieved in the coldest climate zones. As reported in Table 3, night-time natural ventilation control allowing $15 \mathrm{ac} / \mathrm{h}$ of air exchange is able to enhance PCM passive cooling potential up to $10.9 \%$ energy need reduction in Dfc zone (Tarvisio). Furthermore, the same control of free-cooling-based natural ventilation leads up to $68.5 \%$ efficiency in Dfc zone and $12.4 \%$ in Cfa zone (Milan).

Anyway, in general, natural ventilation has demonstrated to influence the effectiveness of PCM implementation as passive strategy for building cooling performance. Such findings could be potentially used even in the design and control of mechanical ventilation.

Table 3: Comparison of cooling need in the main scenarios.

\begin{tabular}{|c|c|c|c|c|}
\hline \multirow{2}{*}{ City } & \multicolumn{4}{|c|}{ Q $_{\text {cooling }}[\mathbf{k W h}]$} \\
\cline { 2 - 5 } & Base & OptPCM & $\begin{array}{c}\text { OptPCM } \\
\text { NV }\end{array}$ & $\begin{array}{c}\text { OptPCM } \\
\text { FC }\end{array}$ \\
\hline Palermo & 73959 & $\begin{array}{c}73913 \\
(-0.06 \%)\end{array}$ & $\begin{array}{c}79526 \\
(+7.53 \%)\end{array}$ & $\begin{array}{c}70881 \\
(-4.16 \%)\end{array}$ \\
\hline Naples & 66970 & $\begin{array}{c}66902 \\
(-0.10 \%)\end{array}$ & $\begin{array}{c}66842 \\
(-0.19 \%)\end{array}$ & $\begin{array}{c}61526 \\
(-8.13 \%)\end{array}$ \\
\hline Rome & 66239 & $\begin{array}{c}66227 \\
(-0.02 \%)\end{array}$ & $\begin{array}{c}65827 \\
(-0.62 \%)\end{array}$ & $\begin{array}{c}61274 \\
(-7.50 \%)\end{array}$ \\
\hline Milan & 60169 & $\begin{array}{c}60151 \\
(-0.03 \%)\end{array}$ & $\begin{array}{c}57722 \\
(-4.07 \%)\end{array}$ & $\begin{array}{c}52727 \\
(-12.4 \%)\end{array}$ \\
\hline Tarvisio & 42532 & $\begin{array}{c}42527 \\
(-0.01 \%)\end{array}$ & $\begin{array}{c}37885 \\
(-10.9 \%)\end{array}$ & $\begin{array}{c}13418 \\
(-68.5 \%)\end{array}$ \\
\hline
\end{tabular}

\section{Conclusion}

Given the significant potential of phase change materials in improving building energy efficiency as passive strategies when integrated into the building envelope, this work assesses the role of natural ventilation control in enhancing such performance. In detail, PCM melting point is firstly optimized in order to minimize building cooling energy need when integrated in the internal building envelope. Therefore, the influence of natural ventilation control in activating PCMs passive cooling potential is investigated by considering two ventilation controls, i.e. night-time and free-cooling based, with different air exchange rates. Results show a significant variation in the efficiency of the thermal energy storage charge-discharge cycle of PCMs integrated in the internal building envelope when varying the considered natural ventilation control and the climate context. In fact, night-time ventilation appears to worsen the passive cooling performance of PCMs in hottest climates up to $7.5 \%$ cooling need increase in Palermo, due to little temperature drop during night. Conversely, ventilation control based on free-cooling availability with high air exchange rate is able to optimize PCMs chargedischarge capability in all considered climate contexts, up to $68.5 \%$ cooling need reduction in the coldest climate of Tarvisio.

According to the promising findings obtained in this work, future studies should further assess optimum control strategies of natural and mechanical ventilation in buildings when coupled with the implementation of 
phase change materials in the external and internal building envelope as passive energy efficiency strategies. Such controls could be actually implemented for the effective management of buildings based on the climate context. Moreover, the same procedure is reproducible for other climate conditions.

\section{Acknowledgement}

This project has received funding from the European Union's Horizon 2020 research and innovation programme under grant agreement No 764025 (SWSHEATING) and the Marie Sklodowska-Curie grant No 712949 (TECNIOspring PLUS) and from the Agency for Business Competitiveness of the Government of Catalonia. GREiA is certified agent TECNIO in the category of technology developers from the Government of Catalonia. This work was partially funded by the Ministerio de Economía y Competitividad de España (ENE2015-64117-C5-1-R (MINECO/FEDER)). The authors would like to thank the Catalan Government for the quality accreditation given to their research group (2017 SGR 1537). The first author wishes to thank Regione Umbria and Department of Engineering at University of Perugia for supporting the project "SMEET-WELL: SMart building managEment for Energy saving meets WELLbeing".

\section{Nomenclature}

$f(x) \quad$ Objective function of the optimization analysis

$x \quad$ Independent variable of the optimization analysis

$X \quad$ Constraint set for the independent variable

$Q_{\text {cooling }}$ Building total energy need for cooling in summer [kWh]

$T_{m, P C M}$ Melting point of PCMs integrated in building internal envelope components $\left[{ }^{\circ} \mathrm{C}\right]$

\section{References}

Antony Aroul Raj, V. and R. Velraj (2010). Review on free cooling of buildings using phase change materials. Renewable and Sustainable Energy Reviews 14, 2819-2829.

ASHRAE (2016). Energy Standard for Buildings Except Low-Rise Residential Buildings (ASHRAE Standard 90.1-2016).

Baetens, R., B.P. Jelle and A. Gustavsen (2010). Phase Change Materials for Building Applications: A Stateof-the-Art Review. Energy and Buildings 42(9), 1361-1368.

Borderon, J., J. Virgone and R. Cantin (2015). Modeling and simulation of a phase change material system for improving summer comfort in domestic residence. Applied Energy 140, 288-296.

Crawley, D.B., C.O. Pedersen, L.K. Lawrie and F.C. Winkelmann (2000). Energy plus: Energy simulation program. ASHRAE Journal 42, 49-56.

Crawley, D.B., L.K. Lawrie, F.C. Winkelmann, W.F. Buhl, Y.J. Huang, C.O. Pedersen, R.K. Strand, R.J.
Liesen, D.E. Fisher, M.J. Witte and J. Glazer (2001). EnergyPlus: Creating a new-generation building energy simulation program. Energy and Buildings 33, 319-331.

de Gracia, A., R. Barzin, C. Fernández, M.M. Farid and L.F. Cabeza (2016). Control strategies comparison of a ventilated facade with PCM - energy savings, cost reduction and $\mathrm{CO}_{2}$ mitigation. Energy and Buildings 130, 821-828.

de Gracia, A., C. Fernández, A. Castell, C. Mateu and L.F. Cabeza (2015). Control of a PCM ventilated facade using reinforcement learning techniques. Energy and Buildings 106, 234-242.

European Committee for Standardization (2007). Indoor Environmental Input Parameters for Design and Assessment of Energy Performance of Buildings Addressing Indoor Air Quality, Thermal Environment, Lighting and Acoustics (EN 15251:2007).

Evins, R. (2013). A review of computational optimisation methods applied to sustainable building design. Renewable and Sustainable Energy Reviews 22, 230-245.

Fabi, V., R.V. Andersen, S.P. Corgnati and B.W. Olesen (2013). A methodology for modelling energy-related human behaviour: Application to window opening behaviour in residential buildings. Building Simulation 6, 415-427.

Figueiredo, A., R. Vicente, J. Lapa, C. Cardoso, F. Rodrigues and J. Kämpf (2017). Indoor thermal comfort assessment using different constructive solutions incorporating PCM. Applied Energy 208, 1208-1221.

Guarino, F., A. Athienitis, M. Cellura and D. Bastien (2017). PCM thermal storage design in buildings: Experimental studies and applications to solaria in cold climates. Applied Energy 185, 95-106.

Kottek, M., J. Grieser, C. Beck, B. Rudolf and F. Rubel (2006). World map of the Köppen-Geiger climate classification updated. Meteorologische Zeitschrif 15, 259-263.

Liu, X., Y. Zhou and G. Zhang (2018). Numerical study on cooling performance of a ventilated Trombe wall with phase change materials. Building Simulation 11, 677-694.

Memarian, S., B.M. Kari, R. Fayaz and S. Asadi (2018). Single and combined phase change materials: Their effect on seasonal transition period. Energy and Buildings 169, 453-472.

Piselli, C., M. Saffari, A. de Gracia, A.L. Pisello, F. Cotana and L.F. Cabeza (2017). Optimization of roof solar reflectance under different climateconditions, occupancy, building configuration and energy systems. Energy and Buildings 151, 81-97. 
Pisello, A.L., V.L. Castaldo, J.E. Taylor and F. Cotana (2016). The impact of natural ventilation on building energy requirement at inter-building scale. Energy and Buildings 127, 870-883.

Presidente della Repubblica Italiana (1993). Decree DPR $412 / 93$ - Regolamento recante norme per la progettazione, l'installazione, l'esercizio e la manutenzione degli impianti termici degli edifici ai fini del contenimento dei consumi di energia, in attuazione dell'art.4, comma 4, della L. 9 gennaio, 1993 (in Italian).

Repubblica Italiana, Ministero dello Sviluppo Economico (2015). Decreto interministeriale 26giugno 2015 - Applicazione delle metodologie di calcolo delle prestazioni energetiche e definizione delle prescrizioni e dei requisitiminimi degli edifici (in Italian).

Rubitherm (2019). PCM RT-line. https://www.rubitherm.eu/en/index.php/productcateg ory/organische-pcm-rt.
Saffari, M., A. de Gracia, S. Ushak and L.F. Cabeza (2017). Passive cooling of buildings with phase change materials using whole-building energy simulation tools: A review. Renewable and Sustainable Energy Reviews 80, 1239-1255.

Saffari, M., C. Piselli, A. de Gracia, A.L. Pisello, F. Cotana and L.F. Cabeza (2018). Thermal stress reduction in cool roof membranes using phase change materials (PCM). Energy and Buildings 158, 1097-1105.

U.S. Department of Energy (DOE) (2016). EnergyPlus Engineering Reference: The Reference to EnergyPlus Calculations, 1444

U.S. Department of Energy's (DOE) Building Technologies Office (BTO) (2016). EnergyPlus Weather Data.

Wetter, M. (2000). Design Optimization with GenOpt. Building Energy Simulation User News 21, 19-28. 